\title{
A SEgURANÇA PÚBliCA NA ATIVIDAde de TRILHA. O CASO DO NÚCLEO CAMORIM - PARQUE ESTADUAL DA PEDRA BRANCA - PEPB / RJ.
}

\author{
Jorcelino Rinalde de Paulo ${ }^{1}$
}

\section{RESUMO}

Atualmente a deficiência de ações e de programas de segurança pública direcionados para atividade de trilha no Núcleo Camorim - Parque Estadual da Pedra Branca (PEPB) - RJ, revela um escopo de discussão que detém alta relevância no processo de gestão pública de áreas naturais protegidas. Nesse contexto, este trabalho possui a finalidade de discutir a emergência dos debates e dos questionamentos sobre a segurança pública dos visitantes adeptos a prática de trilhas no Núcleo Camorim - PEPB - RJ, correlacionando os principais problemas encontrados naquela unidade. Por fim, como sugestão para mitigação e solução da problemática exposta, esta pesquisa propõe, dentre outras alternativas, a composição de comissões especiais responsáveis por estudos de segurança pública preventiva integradas aos gestores responsáveis pelo PEPB, além da estruturação de novos moldes para o programa de uso público de trilhas existente naquela unidade.

Palavras-Chave: Segurança Pública, Uso público de trilhas, Unidades de Conservação.

\begin{abstract}
Currently disability actions and public safety programs designed to track activity in the nucleus Camorim - White Stone State Park (PEPB) - RJ , according to a discussion of scope that has high relevance in the public management process of protected natural areas . In this context, this work has the purpose of discussing the emergence of discussions and questions about the public safety of visitors crowd the practice of trails at the Center Camorim - PEPB RJ , correlating the main problems found in that unit . Finally, as a suggestion for mitigation and solution of the exposed problem, this research proposes, among other alternatives, the composition of special committees responsible for studies of preventive public security integrated with managers responsible for PEPB , besides the structuring of new molds for the program public use of existing trails that drive.
\end{abstract}

Keywords: Public Safety, Public use trails, protected areas.

\section{INTRODUÇÃO}

A ausência e a deficiência da segurança pública nos limites internos do Núcleo Camorim - Parque Estadual da Pedra Branca (PEPB) - RJ, inserido na porção oeste do território da cidade do Rio de Janeiro, em uma região com franca expansão urbana, revela um

\footnotetext{
${ }^{1}$ Mestrando em Engenharia Urbana e Ambiental - PUC-RIO e Technische Universität Braunschweig Alemanha. E-mail: rinaldeambiental@ hotmail.com
} 
novo escopo de discussões que deve ser analisado como um problema de alta relevância para a gestão pública de espaços naturais protegidos.

Esse fato denota uma tendência de insegurança que coloca os indivíduos envolvidos em atividades de trilha naquela região em estado de alerta. Consequentemente este processo incentiva a diminuição do público visitante naquela área, o que contraria a demanda crescente de pessoas que buscam o Núcleo Camorim do PEPB para atividades de lazer e de contato direto com a natureza preservada. Esta ocorrência retrata a urgência com a qual esse problema deve ser amplamente debatido e questionado.

Em consonância com as colocações iniciais, recentemente, os principais meios de comunicação de massa do Rio de Janeiro, noticiaram repetidos assaltos e situações do gênero nos principais parques e unidades de conservação da cidade. Nesse sentido, a violência típica dos centros urbanos que demonstra o cotidiano das grandes metrópoles brasileiras atinge assim mais um patamar, e agora encontra espaço para atuação em áreas ermas e de difícil acesso das unidades de conservação ambiental.

A Constituição da República Federativa do Brasil (BRASIL, 1998) em seu Art.144 descreve que a segurança pública é dever do Estado, direito e responsabilidade de todos, e deve ser exercida para a preservação da ordem pública e da incolumidade das pessoas e do patrimônio, através de diferentes órgãos. A literatura científica disponível para conceituação bibliográfica sobre segurança pública em áreas naturais é extremamente escassa, e com isso, é possível denotar uma deficiência gritante de discussões sobre esse tema.

Observando as características geomorfológicas da região oeste da cidade do Rio de Janeiro e o processo de planejamento urbano desenvolvido ao longo dos anos naquela região é possível destacar que as unidades de conservação existentes naquele território estão envoltas por diferentes estruturas e pressões urbanas. Há nessa relação uma infinidade de conflitos, cuja abordagem será limitada, neste trabalho, ao problema de segurança pública observado no Núcleo Camorim do PEPB - RJ, que representa um alerta aos adeptos da atividade de trilha nas demais unidades de conservação do município.

Nesse sentido, este estudo busca discutir a emergência dos questionamentos sobre a segurança pública do visitante adepto a atividade de trilha no Núcleo Camorim - PEPB, assim como possui a finalidade de debater a adequação de mudanças no processo de planejamento do uso público adotado atualmente naquela unidade.

Diante das discussões abordadas nessa pesquisa espera-se que os resultados obtidos possam ser utilizados para reforçar a proposta de alteração do planejamento e do programa de uso público de trilhas do PEPB - RJ, garantindo assim maior atenção para o aumento da segurança individual de seus visitantes e da qualidade do processo de interação entre o homem e a natureza em áreas naturais protegidas.

\section{OBJETIVOS}

O objetivo geral deste trabalho é identificar a deficiência da segurança pública nas atividades de trilha realizadas no Núcleo Camorim - Parque Estadual da Pedra Branca (PEPB) - RJ. 


\section{MATERIAL E MÉTODOS}

Em síntese, a metodologia empregada neste estudo buscou agregar procedimentos teóricos e práticos que pudessem levar a um maior entendimento sobre o crescente clima de insegurança que atinge diretamente o processo de uso público de trilhas no Núcleo Camorim - PEPB - RJ. Para o desenvolvimento da diagnose desta pesquisa foi realizada uma análise do Plano de Manejo do Parque Estadual da Pedra Branca - PEPB, e também, uma série de visitas de campo junto ao referido Núcleo. Este estudo ainda contou com a realização de diversas atividades de trilha nesta seção da unidade, além de entrevistas diretas com os funcionários guarda-parques do núcleo.

O processo metodológico para esta pesquisa buscou atingir uma coleta de dados que pudesse subsidiar a formulação de questionamentos sobre a segurança pública dos visitantes. A coleta de dados ocorreu entre os meses de setembro e outubro do ano de 2015, particularmente nos dias de sábado e domingo, períodos de maior movimento na unidade de conservação.

\section{RESULTADOS}

Conforme o prescrito no Sistema Nacional de Unidades de Conservação da Natureza, (SNUC), em seu parágrafo $2^{\circ}$, o conceito de Unidades de Conservação é o espaço territorial e seus recursos ambientais, incluindo as águas jurisdicionais, com características naturais relevantes, legalmente instituídos pelo Poder Público, com objetivos de conservação e limites definidos, sob regime especial de administração, ao qual se aplicam garantias adequadas de proteção (WALLAUER, 2003). Esses espaços de acordo com o Ministério do Meio Ambiente e o Instituto Brasileiro do Meio Ambiente e dos Recursos Naturais (MMA/IBAMA, 1997) são apropriados para a aplicação de Programas de Uso Público, cujo objetivo é propiciar o lazer, a recreação e a educação ambiental à comunidade, bem como despertar uma consciência crítica para a necessidade de conservação dos recursos naturais das UCs, além de esclarecer o público, em geral, sobre as responsabilidades, as dimensões e a importância dessas áreas na conservação da biodiversidade.

Nesse contexto, para que haja efetividade no objeto de interação entre o ser humano e o espaço natural em estado de preservação, há necessariamente uma obrigação do Estado em promover esse contato de forma segura e confiável. Portanto, a elaboração e o planejamento de programas de uso público de trilhas que contemplem aspectos efetivos para a garantia da segurança e integridade dos visitantes das unidades de conservação ambiental devem ser priorizados.

\section{Caracterização da área de pesquisa.}

De acordo com a Secretaria Municipal do Meio Ambiente do Rio de Janeiro (SMAC) cerca de $30 \%$ da área total do município do Rio encontra-se sob proteção na forma de Unidades de Conservação (UCs). Nesse espaço geográfico também se encontra o Mosaico Carioca, composto por 2 UCs federais, 4 UCs estaduais e 17 UCs municipais, todas reconhecidas pela Portaria do Ministério do Meio Ambiente n ${ }^{\circ} 245$ de 11 de julho de 2011. 
Essa constituição de UCs possui um importante papel ecossistêmico para o município, além de ser uma ampla área de lazer para cariocas e visitantes da cidade do Rio de Janeiro.

O Parque Estadual da Pedra Branca, de acordo com seu Plano de Manejo atual, possui uma extensão de aproximadamente 12.393,84 hectares e cerca de 80 quilômetros de perímetro, possuindo o Pico da Pedra Branca como seu ponto culminante, com 1.025 metros de altitude, sendo este o mais alto de toda a cidade do Rio de Janeiro. Ainda conforme dados extraídos do Plano de Manejo do PEPB, no acervo cedido pelo Instituto Estadual do Ambiente INEA (2011) relativo ao Anuário Estatístico do Rio de Janeiro (AERJ, 1989), das Florestas Protetoras da União que estão inseridas no PEPB, uma das poucas áreas reconhecidas são as áreas do Camorim com 2.600 ha. Entretanto, essa estimativa deve ser (re) considerada no contexto de falta de informações precisas sobre tamanhos de áreas públicas e privadas no interior do PEPB. A figura 1 permite uma contextualização desta unidade no município e demonstra que o parque situa-se na zona oeste do Rio de Janeiro e faz limite com dezessete bairros distintos.

Figura 1 - Mapa de localização física do Parque Estadual da Pedra Branca.

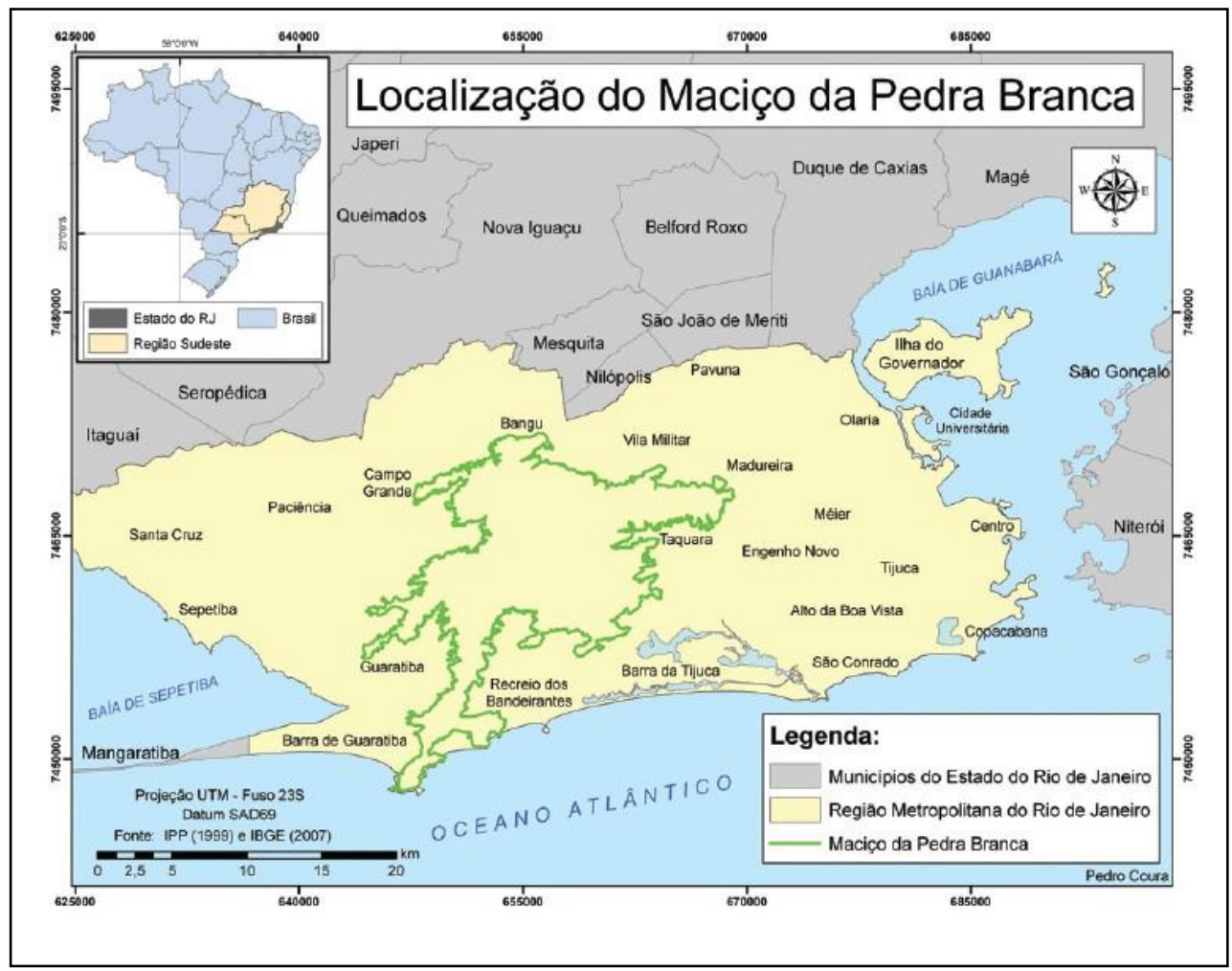

Fonte: Coura, P. F. et al. (2009).

Em recente trabalho realizado por Paulo (2016), no Parque Estadual da Pedra Branca Núcleo Camorim - RJ, uma importante observação foi colocada quanto o aspecto da segurança pública naquela unidade. $\mathrm{O}$ autor descreve que no local existe apenas uma pequena guarnição de guarda-parques, que são funcionários responsáveis por um grande leque de ações e responsabilidades que se estendem desde o controle de entrada de pessoal até o 
combate a incêndios florestais, guarda patrimonial, resgate, socorro individual etc. Com isso, há uma grande deficiência quanto às ações de policiamento e fiscalização durante os trajetos e percursos das trilhas presentes naquela unidade.

No PEPB há um destacamento da Polícia Militar do Estado do Rio de Janeiro, com a finalidade de combater delitos e crimes ambientais, porém está sediado no Núcleo Pau da Fome que é o núcleo central da unidade de conservação. Assim, o uso público de trilhas em toda extensão do PEPB não detém uma ação efetiva de fiscalização e monitoramento relacionados com a segurança pública e pessoal dos adeptos da atividade de trilha na unidade. Essa condição se agrava com o fato de que no Núcleo Camorim existem múltiplos trechos de trilhas permeados por entradas clandestinas e secundárias, que dão acesso direto a diferentes pontos da zona oeste da cidade do Rio de Janeiro.

Em consonância com as informações apresentadas por Paulo (2016) a Tabela I descreve uma série de dados que demonstra os principais problemas de segurança pública percebidos durante as atividades de trilha e visitas de campo realizadas naquele núcleo do parque. As informações apresentadas foram coletadas entre os meses de setembro de outubro do ano de 2015.

Tabela I - Problemas e ações propostas sobre a segurança pública no Núcleo Camorim -

$$
\text { PEPB - RJ. }
$$

\begin{tabular}{|c|c|}
\hline Problemas Encontrados & $\mathbf{A S}$ \\
\hline $\begin{array}{l}\text { Defici } \\
\text { ogramas } \\
\text { seguran }\end{array}$ & $\begin{array}{l}\text { - Composição de comissão especial in } \\
\text { unidade, que trate de estudos destinad } \\
\text { inteligência operacional e de seguran } \\
\text { público de trilhas e às instalações físic }\end{array}$ \\
\hline $\begin{array}{l}\text { Múlti } \\
\text { secun } \\
\text { munica } \\
\text { ão ofic } \\
\text { de ce }\end{array}$ & $\begin{array}{l}\text { - Instalar um plano de mo } \\
\text { clandestinas do Núcleo p } \\
\text { um programa de patrulha } \\
\text { da unidade. }\end{array}$ \\
\hline fi & ção nos \\
\hline '́lo & trilhas \\
\hline $\begin{array}{l}\text { Risco } \\
\text { probleı } \\
\text { públic } \\
\text { internos }\end{array}$ & $\begin{array}{l}\text { - Propor uma relação amigável entre os agentes de segurança } \\
\text { pública responsáveis pela fiscalização da unidade e os visitantes } \\
\text { do núcleo, em busca de uma integração entre a segurança e o bem } \\
\text { estar dos indivíduos visitantes e a permanente proteção das áreas e } \\
\text { instalações da unidade de conservação. }\end{array}$ \\
\hline $\begin{array}{r}\text { Dificuldade } \\
\text { comunicação c } \\
\text { Guarda-Parques } \\
\text { de emergência de }\end{array}$ & $\begin{array}{l}\text { - Implantar e operacionalizar um sistema de comunicação integrada } \\
\text { entre os pontos turísticos de interesse do núcleo e a sede do } \\
\text { Camorim. (Ex: Tel. público ou rádio comunicador instalado em } \\
\text { base fixa implantada nas imediações do Açude do Camorim, etc.). }\end{array}$ \\
\hline
\end{tabular}


Os problemas de segurança pública identificados no Núcleo Camorim estão permeados pela ausência de um sistema integrado de segurança pessoal, cujo objeto seja transmitir maior segurança individual os visitantes da unidade. Assim, como proposta efetiva para solução e mitigação dessa deficiência é possível sugerir aos gestores do PEPB a adoção e o emprego de um programa de segurança preventiva integrada que aborde questões relacionadas com a inteligência operacional em áreas naturais protegidas, cuja efetivação pode ser realizada por meio de consultoria ou parcerias com empresas e profissionais qualificados na área em questão.

A carência da segurança pública em áreas naturais localizadas em grandes centros urbanos, como a cidade do Rio de Janeiro, principalmente em períodos de férias escolares ou em momentos de grandes eventos, como os jogos olímpicos de 2016, resulta em graves problemas para o processo de uso público de trilhas nas unidades de conservação no município. Estudos revelam que atualmente, com o turismo ecológico, diferentes grupos sociais buscam uma reaproximação com os ambientes naturais, com isso, ocorre um aumento considerável na demanda por áreas naturais protegidas (TAKAHASHI, 1998). Esses dados demonstram que a segurança pública em áreas naturais é um assunto que merece destaque e que deve ser tratada de forma urgente e direcionada.

Na figura 2 é possível perceber que a quantidade total de indivíduos visitantes do Núcleo Camorim entre os anos de 2013 e 2014, nos meses de setembro e outubro respectivamente foi bastante significativa, o que denota a importância de se pensar em um programa de segurança pública preventiva que atenda eficientemente o público visitante deste núcleo do Parque Estadual da Pedra Branca.

Figura 2 - Número de visitantes do Núcleo do Camorim registrado entre os meses de setembro e outubro dos anos de 2013 e 2014, respectivamente.

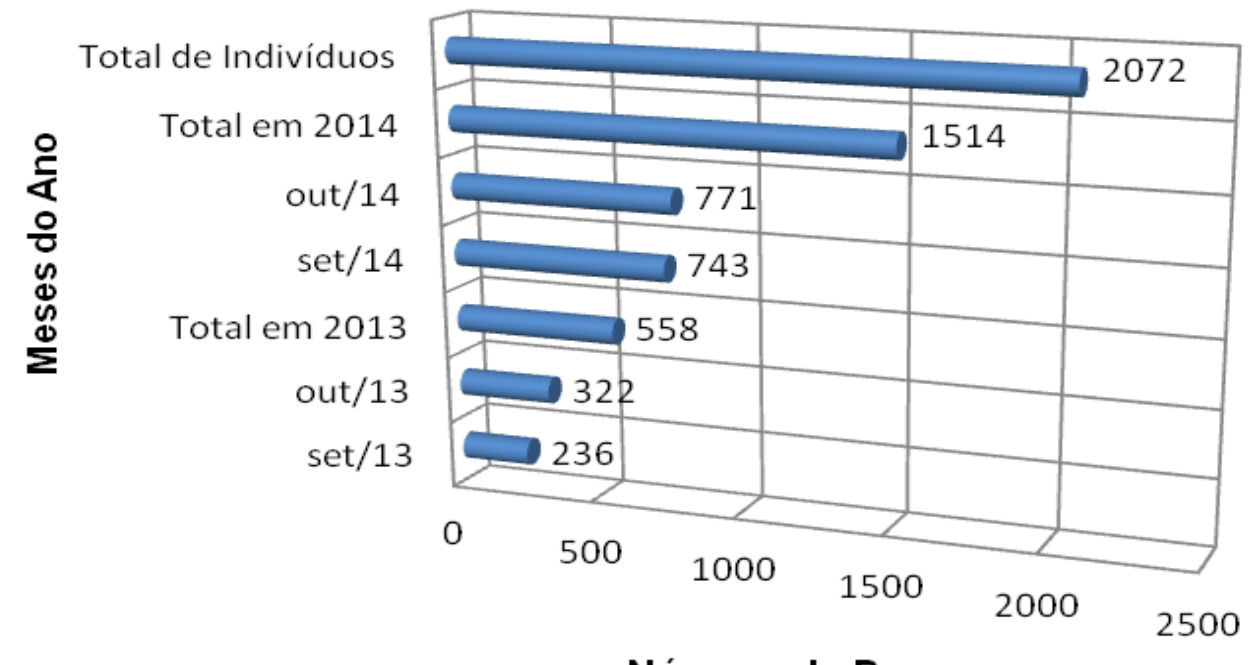

Fonte: Autor. 
Diante da contextualização da discussão sobre a deficiência da segurança pública no Núcleo Camorim - PEPB é possível identificar que a promoção de novas formas de planejamento para o uso público de trilhas, nesta unidade de conservação, representa uma grande oportunidade para se pensar em modelos de uso público mais eficientes e seguros, que proporcionem aos adeptos da atividade de trilha uma condição essencial para sua realização de forma adequada e efetiva.

Conforme Paulo (2016) uma proposta eficaz para o combate inicial a essa problemática é a composição de comissões especiais que tratem de estudos destinados a utilização de técnicas de inteligência operacional e de segurança orgânica aplicadas ao uso público de trilhas e às instalações físicas das áreas de preservação ambiental. Tais medidas podem ser adotadas por meio de cursos, palestras, convênios ou parcerias com profissionais qualificados e instituições especializadas nas áreas de segurança pessoal e de instalações, cujo objetivo seja a diminuição do clima crescente de insegurança na prática do uso público de trilhas em UCs. Essas ações necessitam ser pensadas e planejadas tanto pelo órgão responsável pela gestão pública do PEPB quanto pelos órgãos de segurança pública do Estado do Rio de Janeiro.

Nesse sentido, este estudo propõe múltiplas ações que sugerem diferentes pontos para reflexão sobre as discussões e debates a respeito da segurança pública em áreas naturais protegidas. Em última análise é importante salientar que as propostas relatadas por este trabalho não esgotam, mas sim iniciam as discussões sobre o tema abordado.

Assim, após a realização e análise da breve discussão sobre os problemas e propostas de soluções relacionados com a segurança pública e pessoal dos visitantes adeptos da atividade e trilhas no Núcleo Camorim - PEPB - RJ, é possível identificar que o núcleo possui uma grande carência no quesito segurança pública. Nesse contexto, o presente trabalho indica a necessidade de estruturação de novos moldes para o programa de uso público da unidade, planejando-se com foco na segurança pessoal do visitante. Esta poderá ser uma excelente oportunidade de melhoria e adequação do potencial turístico-recreativo que o núcleo detém, além de auxiliar diretamente a preservação dos ecossistemas florestais e mananciais hídricos presentes naquela parte da unidade de conservação ambiental.

\section{CONCLUSÕES E RECOMENDAÇÕES}

A partir dos dados relatados neste estudo pode-se concluir que a inserção de programas de segurança pública no Núcleo Camorim - PEPB - RJ, relacionados com atividades de uso público de trilhas, necessitam urgentemente de discussões e atitudes diretas dos órgãos competentes do Estado. Portanto, em busca de um maior compromisso e da garantia de não só proteger as áreas físicas da unidade, como também a salvaguarda do bem estar de seu maior e mais importante colaborador, o público visitante. A reflexão sobre essa possibilidade, por parte dos gestores atuais do PEPB, é uma importante atitude a ser tomada. Sob a visão dos dados apresentados nesse estudo é possível refletir que, efetivamente, as medidas por ele proposta podem gerar inúmeros resultados positivos para a gestão pública de espaços protegidos em curto espaço de tempo. 
Por fim, como recomendação para trabalhos futuros que abordem a temática exposta nessa pesquisa sugere-se a ampliação dos questionamentos apresentados, bem como uma maior amplitude da área delimitada para pesquisa, objetivando assim, uma melhor compreensão dos problemas de segurança pública existentes nas diferentes unidades de conservação ambiental inseridas no grande aglomerado urbano da cidade do Rio de Janeiro.

\section{REFERÊNCIAS BIBLIOGRÁFICAS}

BRASIL. Artigo 144. Jul. 2016. Disponível em: < http://www.planalto.gov.br/ccivil_03/Constituicao/Constituicao.htm> Acesso: 21/07/2016.

BRASIL. Lei $\mathbf{N}^{\circ}$ 9.985, de 18 Julho de 2000. Dispõe sobre Sistema Nacional de Unidades de Conservação da Natureza (SNUC). Publicado no Diário Oficial da União de 18 Julho de 2000 .

COURA, Pedro Henrique Ferreira; SOUSA, Gustavo Mota de; FERNANDES, Manoel do Couto. Mapeamento geoecológico da susceptibilidade à ocorrência de incêndios no maciço da Pedra Branca, município do Rio de Janeiro. Anu. Inst. Geocienc., Rio de Janeiro, v. 32, n. 2, dez. 2009.

Instituto Estadual do Ambiente Trilhas- 2013. Parque Estadual da Pedra Branca - Instituto Estadual do Ambiente - Organizado por André Ilha, Patrícia Figueiredo de Castro, Alexandre Marau Pedroso, Aline Schneider - Rio de Janeiro: INEA, 2013

MMA/Ibama. Marco Conceitual das Unidades de Conservação Federais do Brasil. Brasília: MMA/Ibama/Direc/GTZ. 1997.

PAUlO, J. R. O Uso Público de Trilhas em Unidades de Conservação e suas InterRelações com a Gestão de Recursos Hídricos. Monografia (Especialização). Setor de Engenharia Sanitária e Ambiental - Universidade do Estado do Rio de Janeiro, 2016.

PORTARIA No- 245, DE 11 DE JULHO DE 2011 A MINISTRA DE ESTADO DO MEIO AMBIENTE, no uso de suas atribuições, e tendo em vista o disposto na Lei no 9.985, de 18 de julho de 2000, e nos arts. 8 o ao 11 e 17 a 20 do Decreto no 4.340, de 22 de agosto de 2002, resolve: Art. $1^{\circ}$ Reconhecer o Mosaico Carioca.

SECRETARIA MUNICIPAL DO MEIO AMBIENTE DO RIO DE JANEIRO - SMAC. Jul. 2016. Disponível em: < http://www.rio.rj.gov.br/web/smac/unidades-de-conservacao $>$ Acesso: 21/07/2016.

TAKAHASHI, L.Y. Caracterização dos visitantes, suas preferências e percepções e avaliação dos impactos da visitação pública em Unidades de Conservação do Estado do Paraná. 1998. Tese (Doutorado). Setor de Ciências Agrárias, Universidade Federal do Paraná, Curitiba, 1998. 
WALlAUER, M. T. B. Sistema Nacional de Unidades de Conservação - SNUC. In: ENCONTRO PRESENCIAL DA FUNIBER, 2003, Florianópolis. Aula Presencial Arquivos com as Palestras. Florianópolis: FUNIBER, 2003.

WARD, A. D.; TRIMBLE S.W. Environmental hydrology, New York: Lewis Publishers. 2004. 